\title{
La historia de Oaxaca vista por los historiadores oaxaqueños *
}

Margarita Dalton

\author{
Al Lic. Luis Castañeda Guzmán, con el \\ respeto que merecen los maestros
}

\begin{abstract}
Si
i consideramos que la historia es la experiencia social y colectiva del pasado de un pueblo, podemos también afirmar que es la memoria y la identidad que caracteriza a una etnia, a una nación y a
\end{abstract} un país.

La historia del estado de Oaxaca no puede ser una sola versión de los acontecimientos del pasado, de hecho no lo es. Hay varias versiones y sólo se estará cerca de la verdad sobre lo que aconteció si se utiliza el método de comprobación, análisis, crítica e interpretación de las fuentes.

Los últimos cien años, especialmente, presentan un mosaico de múltiples versiones: detrás de cada una hay una razón: es necesario conocer el origen social, la condición económica y las ideas políticas de quienes escribieron la historia para ver qué interés representaban. Por eso la historiografía que se dedica al estudio de los textos de historia, también está interesada en conocer quiénes escriben los textos y cuáles son los compromisos que tienen con el círculo social en el que se desenvuelven. Asimismo, es imprescindible conocer el momento en que la historia fue escrita.

Si pensamos exclusivamente en la historia de Oaxaca, podemos decir que la conquista fue un parteaguas para sus habitantes. Los recién llegados se apoderaron del espacio de quienes estaban viviendo aquí y se apoderaron del tiempo histórico. Se conoce por los códices, por la escritura maya, por la tradición oral y otros testimonios, que habia relaciones históricas entre los pueblos prehispánicos y también un tiempo histórico propio con parámetros filosóficos distintos a los españoles. A partir de la conquista, el tiempo histórico europeo enmarcará los acontecimientos de esta tierra; es el tiempo histórico delimitado por la existencia de Cristo, antes o después de él. Se puede decir que es éste el primer ajuste histórico que sufren los pueblos mesoamericanos; de esta forma, la cronología anterior también se conquista, clasifica y ordena de acuerdo con el tiempo histórico europeo.

La significación del tiempo histórico, su utilidad, su función, es servir precisamente para ordenar los acontecimientos y sistematizar su interpretación. Gracias a él se pueden constatar los ciclos que marcan un determinado desarrollo. Sin embargo, el tiempo histórico sirve también para vincular los acontecimientos entre si y ajustar su interpretación a la normatividad de la ideologia dominante.

* Este artículo es resultado de un curso-panel impartido en la Maestría de Estudios Regionales del Instituto de Investigaciones Dr. José María Luis Mora, con el nombre de "Historiografia Regional de México", del 16 de junio al 12 de septiembre de 1986. 
Para aproximarse al estudio de la historiografia oaxaqueña se puede empezar por el momento en que se establece el tiempo histórico europeo, es decir, inmediatamente después de la conquista y durante el periodo colonial. Para analizar el tiempo histórico anterior todavía no se cuenta con los elementos necesarios, y menos aún para una historiografía del tipo que se pretende aquí: es decir la función del ser humano que interpreta la historia, en la misma historia. Dentro de este contexto se encuentra que las primeras narraciones históricas sobre Oaxaca están escritas por conquistadores y frailes españoles. Son ellos la representación intelectual del régimen monárquico y de la Iglesia.

El cronista Bernal Diaz del Castillo, en su Historia verdadera de la conquista de la Nueva España, ya nos habla de cómo Rodrigo Rangel pacifica a los pueblos zapotecas y a "Zimatlan", de las habilidades de los chinantecos y de la lucha que los españoles tienen en el reino de Tututepec. Es un español señalando y describiendo el nuevo mundo con mirada europea. No sólo eso, sino con intereses totalmente ajenos a los pobladores de todas estas tierras que ellos, los europeos, llamaron del Nuevo Mundo.'

Este tipo de crónica que se vuelve un testimonio histórico, por muy valioso que sea, impone una ideología y una interpretación de los hechos. Es interesante lo que aquel español vio en estas tierras pero surge la pregunta: ¿Cuál sería la versión de los vencidos? Hace falta la visión de los zapotecas, de los chinantecas, etc. ¿Se podrán recuperar todavia testimonios, mantenidos a través de la tradición oral, sobre lo que pensaron los zapotecas o chinantecas de los españoles? Se sabe que en la actualidad existen trabajos abocados a realizar nuevas interpretaciones de la historia de Oaxaca desde el punto de vista de los diversos grupos étnicos. Sería necesario hacer una investigación rigurosa de cuáles son en la actualidad las reminiscencias que de aquel primer encuentro han quedado en la tradición oral, en los bailes y en las fiestas.

Después del cronista conquistador, son los frailes españoles quienes serán también cronistas e historiadores. Son los frailes quienes están mejor preparados para leer y escribir, quienes tienen mayor contacto en la vida cotidiana con los pueblos y las comunidades de Oaxaca; se van a vivir con los zapotecas y aprenden su idioma, escriben incluso sobre el Arte del idioma zapoteca. ${ }^{2}$ Aprenden también mixteco, mije y todas las lenguas que se hablan en Oaxaca para poder conquistar el espíritu de los pueblos con la religión cristiana e imponer así una nueva ideología.

Entre estos conquistadores de las mentes y de las ideas, están aquéllos que defenderán a los "indios" de los malos tratos corporales y de los abusos materiales de los conquistadores. Quienes conquistan la mente son quienes defienden el cuerpo.

Hasta ahora, se ha considerado a fray Francisco de Burgoa como el primer historiador oaxaqueño, debido a dos libros fundamentales para el estado, escritos por él: La palestra historial y la

\footnotetext{
1 Bernal Diaz del Castillo, Historia verdadera de la conquista de la Nueva España. La Habana, Editora del Consejo Nacional de Cultura, 1963, 2 t.

${ }_{2}$ Fray Juan de Córdova, Arte del Idioma Zapoteca, Morelia, Imprenta del Gobierno, 1889.
} 
Geográfica descripción. ${ }^{3}$ Se puede decir que son las dos primeras obras que narran la apreciación del espacio y del tiempo oaxaqueños. La información primaria de Burgoa nace de su propia observación del paisaje, así como de la comunicación directa con zapotecos, mixtecos, mijes y otros.

Son pocos los datos biográficos que de él se tienen. Nace en Oaxaca alrededor del año 1600 . Descendiente de los primeros conquistadores y relacionado con la nobleza de la ciudad, muestra desde temprana edad inclinación hacia el estudio. Su madre es Ana de Porras y Alvarado. No se sabe el nombre de su padre. En 1618 ingresa como novicio al convento de Santo Domingo, y el 2 de agosto de 1620 profesa como sacerdote; cinco años más tarde obtiene el sacerdocio en la orden dominicana. Gran lector y para muchos un erudito, fue profesor de teologia y hablaba perfectamente el mixteco y el zapoteco. En 1649 fue electo provincial de su orden; por tal motivo visitó casi toda Oaxaca. Estos viajes le sirvieron para recolectar información sobre las antigüedades zapotecas y mixtecas y escribir más tarde su obra histórica. En 1656 viaja a Roma y recorre Europa visitando los principales conventos, bibliotecas y museos. ${ }^{4}$

Al regreso de Europa, termina su obra. Hay una nota en la biografía de Burgoa que escribe Martínez Gracida, interesante en lo que se refiere a la construcción y el método de la obra "Nombrado el R.P. Burgoa Vicario de la parroquia de Zaachila, capital que había sido del reino zapoteca, predicó allí el Evangelio a los descendientes del valiente y político rey Cosijoesa, al mismo tiempo que consultaba con ellos sus documentos para legar a Oaxaca su historia."

Mientras está escribiendo su obra, suceden las rebeliones de Tehuantepec, Nejapa, Ixtepeji y Villa Alta (1660), y a pesar de ser zapotecos los protagonistas y de que por su autoridad dentro de la Iglesia y de la orden de Santo Domingo de Guzmán en Oaxaca, Burgoa dio seguramente opiniones e ideas para la solución del conflicto, no habla de ellas en sus libros. ${ }^{6}$

El decreto, las licencias, las calificaciones y aprobaciones que su obra recibe para ser publicada en 1669 , muestran la representatividad de que era acreedor Burgoa dentro del régimen colonial español. Siendo Vicario General calificador de la Suprema Inquisición de España, comisario de ella, revisor de libros y visitador de las bibliotecas de la Nueva España, conoce muy bien lo que puede ser censurado. Asi, cuando el calificador del Santo Oficio tiene que dar su opinión sobre la obra de Burgoa no puede menos que decir "Sane authoritas tanti nominis prima fronte Prelati totum ex inceps comendabilius reddit opus", es una obra altamente recomendada por "quienes saben".

\footnotetext{
${ }^{3}$ Francisco de Burgoa. Palestra historial, México, Publicaciones del Archivo General de la Nación, 1934. Geográfica descripción, México, Publicaciones del Archivo General de la Nación, 2 t.

+ Burgoa. Palestra..., p. X, XI.

5 Burgoa, Ibidem, p. XII.

- Véase, sobre la rebelión de Tehuantepec, Luis González Obregón, Las sublevaciones de indios en el siglo XVII. México, Imprenta del Museo Nacional, 1907, p. 18-29 y Basilio Rojas, La rebelión de Tehuantepec, México, Sociedad Mexicana de Geografia y Estadística, 1964.
} 
Leyendo sus textos se percibe que toda la información que recibe Burgoa pasa a través del cristal ideológico de un fraile culto. $\mathrm{Su}$ mente se ha nutrido de las ideas que prevalecen en Europa, pero les ha añadido los antecedentes mágicos de la tierra propia; el sincretismo de lo sobrenatural no está ausente: nos habla de constelaciones propicias y astros en conjunción, a la vez que del demonio, del príncipe del averno, de "hiel de dragones", "de los humos que exhalaba el corrupto y pestifero licor..." de los pactos con el demonio, de hechiceros y brujos o nahuales, de conjuras propiciadas por la idolatría. Hay descripciones, a veces semejantes a las que podemos encontrar en un libro muy contemporáneo, como El nombre de la rosa, de Umberto Eco. Porque en cuanto a creencias, pese a que habia pasado el Renacimiento europeo, la mentalidad que prevalece en su obra es más afín a la de la Edad Media tardía que a la del Renacimiento. Burgoa muere en Zaachila en 1681 .

Después de Burgoa existen varios otros frailes viajeros que se dedican a describir, de paso por Oaxaca, el paisaje y las costumbres, alabando las cualidades intrinsecas de los pobladores de estas tierras, por ejemplo, su inclinación a la música y al canto, tal es el caso de fray Francisco Ajofrín, capuchino del siglo xviII (1765).

También existen viajeros extranjeros, que con otros ojos e intereses describen a Oaxaca. Tal es el caso de Tomás Gage que viaja por toda América Latina en el siglo XVII y de quien Salvador Bueno sospecha "fue un agente británico infiltrado en las colonias españolas." Pasa por Oaxaca en 1624 , y retrata la ciudad con un lenguaje llano e informativo:

Su vecindario apenas llegará a dos mil personas; está gobernada por un alcalde mayor, cuya jurisdicción se extiende más allá del Valle hasta Nijapa y casi hasta Tecoantepeque, que es un puerto sobre el Mar del Sur.

El Valle tendrá unas quince millas de largo y diez de ancho, y lo riega un río muy abundante de pesca que pasa por medio.

Cúbrenlo muchos rebaños y vacadas, y provee de lanas las fábricas de paño de la Puebla de los Angeles, de cueros a los mercaderes de España, de carnes la ciudad de Oaxaca y todas las demás del contorno que son extremadamente ricas y mantienen muchos conventos de religiosos y muchas iglesias con sus ornamentos. ${ }^{10}$

A su paso por Tehuantepec, la información está llena de contenido politico. No en vano Salvador Bueno sospecha de sus intenciones.

Tecoantepeque no presenta ni sombra de fortificación, y si los corsarios ingleses y holandeses quieren fondear en su puerto, en lugar de resistencia hallarán una rada enteramente abierta para correr todo el pais.

${ }^{7}$ Burgoa, Palestra..., op. cit., p. XIII.

${ }^{8}$ Francisco Ajofrín, Archivo Documental Español, Madrid, Real Academia de Historia, t. XIII, MCMLIX.

${ }^{9}$ Thomas Gage, Viajes en la Nueva España, La Habana, Casa de las Américas, 1980 .

${ }^{10}$ Ibidem, p. 86 . 
En toda la extensión de la costa de la Mar del Sur desde Acapulco hasta Panamá, que se alarga más de seiscientas cincuenta leguas, no hay más puertos que éste en el distrito de Oaxaca, el de la Trinidad en la provincia de Guatemala y el de Realejo en la de Nicaragua, y en el Golfo de las Salinas para las pequeñas embarcaciones que van a la Costa Rica, puertos sin artillería y abiertos a cuantos quieran dar la vuelta al mundo para enriquecerse. ${ }^{11}$

Lo importante de este viajero inglés es su estilo llano que sin grandes artilugios presenta la personalidad de los distintos pueblos oaxaqueños con los que se encuentra. Sus intereses eran externos a Oaxaca: también lo eran sus interpretaciones.

A mediados del siglo XVIII, nace en Oaxaca (1769), don José María Murgía I Galardi, a quien se ha considerado el padre de la estadistica de esta región. Hijo de los señores Lorenzo Justo de Murgía y Cordero, "natural de la ciudad y el puerto de San Cristóbal de la Havana, y María Agustina de Galardi y Zárate, natural de esta ciudad". ${ }^{2}$ José María hizo sus estudios en el seminario de Santa Cruz, donde obtuvo el grado de bachiller. Seguramente le tocó en suerte tomar clases con maestros tan distinguidos como el Sr. Mociño. Toda, o casi toda su obra está inédita, y buena parte perdida o en el extranjero, principalmente en Texas. Su padre fue funcionario español y comerciante, y él es hacendado y funcionario de los insurgentes y de los realistas. ${ }^{13}$

José María Murgía I Galardi escribió Apuntamientos estadisticos de la provincia de Oaxaca de esta Nueva España, que comprende dos partes; la primera sobre sus antigüedades y la segunda sobre su estado actual. De su magna obra hizo varios extractos de los que sólo se conocen Memorias de agricultura, ganadería, artes $e$ industrias, "escrita a pedimento del Sr. Gobernador del centro para dar cumplimiento a supremas disposiciones..."14

A mediados del siglo pasado se imprimieron algunos de sus trabajos. Entre otros, la Sociedad Mexicana de Geografía y Estadística publicó su "Estadística antigua y moderna de la provincia hoy estado libre, soberano e independiente de Guajaca", "trabajo que contiene en la primera parte una reseña histórica de la ciudad de "Guajaca"; enumeración de los obispos que tuvo de 1535 a 1820 y de los gobernadores de 1581 a 1822 , y principales pueblos y haciendas. La segunda parte se refiere al número de habitantes por cada departamento, movimiento de población y producto de las ventas públicas en 1832, 1834, 1833 a 1838, 1841, 1845, 1849, 1851 al 1852 y 1857 ; valor y cantidad del grano exportado de 1785 a 1858 y recondiciones mensuales.

Por lo que viejos historiadores del estado dicen de ellas se conoce la existencia de otras obras. De esta forma se sabe que un trabajo titulado "Extracto general que abraza la estadística toda

"Ibidem, p. 90.

12 Luis Castañeda Guzmán, entrevista, 15 de noviembre 1985.

13 Ibidem.

14 José Maria Miguel I Vergés, Diccionario de Insurgentes, México, Porrúa, 1969.

15 José María de Murgía I Galardi, "Estadistica antigua y moderna de la provincia hoy estado libre soberano e independiente de Guajaca", Boletín de la Sociedad Mevicana de Geografía y Estadística, núm. 7, edición 1859, p. 161-275. 
del Estado de Guajaca y que ha resumido de orden del Supremo gobierno el intendente de la provincia... Don José María Murgía I Galardi, año de 1827" estaba en la biblioteca particular de monseñor Gracida, quien se la mostró al Lic. Castañeda Guzmán y le permitió consultarla, "eran como doscientas o trescientas páginas, ahora se ha perdido". 16

La obra de Murgía I Galardi más conocida es Memoria estadística de Oaxaca y descripción del Valle del mismo nombre, publicada en 1821 , es un extracto "de la que en grande trabajó el Señor Don José María Murgia I Galardi diputado a cortes por aquella provincia. La publica el Licenciado Don Carlos María Bustamante... Veracruz, en la Imprenta Constitucional..." en México de la obra de Murgía I Galardi lo tiene la Sociedad de Geografía y Estadística.

En el siglo XIX. otro historiador oaxaqueño, Juan Bautista Carriedo, produce dos obras, importantes para la historiografia por su estilo personal: Ensayo histórico-estadístico del Departamento de Oaxaca y Estudios históricos y estadisticos del Estado Oaxaqueño. Escribe por amor al terruño como él mismo declara en su ensayo... "...las ideas vertidas en este libro son nacidas de un corazón que desea ardientemente la gloria y engrandecimiento del suelo oaxaqueño". Su concepción de la historia está señalada en la introducción a sus estudios históricos... "El hombre viene actuando como elemento social en el tiempo y en el espacio, en la tierra oaxaqueña desde las épocas más lejanas de que se tenga idea". ${ }^{18}$

En su ensayo histórico-estadístico hace una acuciosa descripción de la naturaleza, de los distintos árboles y frutas de la tierra. Para algunas de sus descripciones geográficas señala a Humboldt como autoridad:

Las montañas en el Departamento son tantas, que numerarlas sería cansado. No todas las altitudes de ellas están reconocidas. La cordillera del cerro de San Felipe del Agua, es la que dice Humboldt, que proviene de los Andes hasta perderse en los Estados Unidos de América; San Juan del Estado o cumbres de este pueblo, cuesta de Cuicatlán, cuesta de Tlacuache, cerro de San Agustín, cerro de S. José, cerro de Tilantongo y Teosacoalco, de Teposcolula, de Sola, Yolotepec, Lachao, Loxicha, La Paguia, San Bartolo, Narro, Antiguo Corte y algunos otros son los notables. ${ }^{19}$

\footnotetext{
16 Angel Taracena, "Gobernantes de Oaxaca: Don José María Murgía y Galardi" Oaxaca Gráfico, domingo 15 de enero de 1967.

17 José Murgia y Galardi, Memoria Estadistica de Oaxaca y descripción del mismo nombre, estractada de la que en grande trabajó el Señor Don José Murgia y Galardi diputado en Cortes por aquella provincia publicada por el Licenciado Don Carlos Maria Bustamante. Individuo de la sociedad patriótica de Guatemala, con una descripción del antiguo palacio de Mictla, e historia militar de los Indios zapotecos, Veracruz, Imprenta Constitucional, 1821.

18 Juan Bautista Carriedo, Ensayo Historico-Estadistico del Departamento de Oaxaca, Oaxaca, Imprenta del Estado, editor Lic. Manuel C. Brioso, 1889, p. 79. Estudios históricos y estadísticos del Estado oaxaqueño. México. Biblioteca Asuntos y Autores Oaxaqueños. talleres de Adrián Morelos, 1949, 2 t.

${ }^{19}$ Ensayo histórico, op. cit., p. 27.
} 
Hace la relación de los hospitales existentes en Oaxaca durante los siglos XVII y XIX basado en las estadísticas económicas con que cuentan los hospitales y en sus gastos. Son datos incompletos por lo que es de suponer que consultó los archivos de los hospitales para sus cifras, aunque no lo mencione directamente. También al hablar del Instituto de Ciencias y Artes se refiere a su biblioteca "...que no es la más abundante, hay buenas obras y muchas cedidas por sujetos particulares, entre ellas hay un atlas manuscrito por el Sr. Millefforont, de las ruinas de Mitla, y cuyos planos y vistas están perfectamente sacados". ${ }^{20}$

En esta obra también traza la personalidad oaxaqueña en sus distintos estratos sociales y en las diferentes regiones. Habla de "indios" y "negros" así como de la clase "alta" de la "media" y de la "baja", reseña las artes y oficios que más abundan en el estado y las cualidades y defectos de sus habitantes. Se puede decir que su estilo es muy sui generis; por momentos está plagado de cifras, gastos de mantenimiento de los hospitales, crecimiento de la población, número de sacerdotes o de niños que asistían a la escuela en 1837 comparados con los de 1839 , etc., y en otros es simplemente la crónica del día, fresca y jugosa: "De veinte años a esta parte se ven en el Departamento fábricas de aguardiente, molinos de aceite, fábricas de vidrios, pailas de jabón y algunas otras ocupaciones industriosas; existen algunos artesanos que sin rudimento alguno se han dedicado a la mecánica ventajosamente". ${ }^{2 !}$ Hablando de la gente, de sus paisanos, se expresa de este modo: "Así como la naturaleza embelleció el Departamento con las alhajas de sus primores, así dotó a sus habitantes de un carácter suave y de un entendimiento capaz de recoger y desenvolver toda especie de cultura. Con poco afán concibe las materias más difíciles y su genio es previsor y fecundo." 22

Al final expresa una serie de consideraciones morales sobre los principales problemas de Oaxaca en relación a su desarrollo y crecimiento, destacando la importancia de la educación: "...habiendo jóvenes con instrucción habrả verdaderos ciudadanos... la instrucción pública es la primera atención de un gobierno sabio... la industria para su desarrollo requiere aulas". Con respecto a otros problemas del desarrollo en el estado, sus opiniones son muy concretas: "La agricultura está ahora lo mismo que hace trescientos años: no se encuentran nuevos plantíos de linos, moreras ni olivos; los instrumentos de labor no tienen nuevas perfecciones; los terrenos no están bien repartidos, unos y otros existen completamente abandonados por falta de brazos... La agricultura necesita tiempos bonancibles y de quietud; porque siendo lentas sus operaciones, cuando hay confianza bastante, se podrán aventurar capitales para su fomento..."23

Para sus Estudios históricos y estadisticos del estado Oaxaqueño es Burgoa la fuente fundamental; así, cuando habla del siglo: $X V I$, sigue la descripción de Oaxaca que hace el fraile en 1617 y

20 Ibidem, p. 37.

21 Ibidem, p. 56.

II Ibidem. p. 59.

${ }^{23}$ Ibidem, p. 72. 
aclara: "El estracto que he hecho para evitar las disgresiones de que abunda aquel escritor...", 24 aclaración que permite saber cuáles son sus apoyos documentales para la historia antigua de Oaxaca; desgraciadamente esto no sucede muy a menudo y muchas veces no se sabe de dónde procede la información. Carriedo es un autodidacta, un historiador sin formación académica; sus lecturas parece que fueron muy dispersas y las cita sin mayor rigor. Sin embargo, se puede aventurar que quien no desee leer a Burgoa directamente, por ser su lenguaje bastante barroco y tener innumerables citas "disgregadoras", puede encontrar en Carriedo la misma información escrita con mayor sencillez, ligereza y amenidad.

En cuanto a su concepción del mundo, hay en Carriedo una inclinación a reivindicar a los autóctonos, principalmente a los zapotecas, mistecos, mijes, etc. Carriedo es un liberal, y considera importante transformar la narración histórica, cosa que intenta, pero hay desfases continuos que se manifiestan en la obra, dándonos una idea de la mentalidad de la época. Además los hechos están interpretados, como por ejemplo en la descripción que del nahual hace:

El nahual en la antigüedad equivalía a un bautismo, por la ceremonia de imponer nombre y lo que hacian los sacerdotes era la consagración que se hacía de la criatura a las divinidades, dándoles el nombre que les tocaba conforme al día del nacimiento, poniéndoseles nombres de plantas o animales, si así se apellidaba el día; sangraban la criatura de una vena detrás de las orejas, con instrumento de pedernal o hueso, o con la uña del índice, que por lo regular era muy crecida en los sacerdotes: quedaba marcada la criatura después de ofrecer la sangre a la divinidad, señalándole al punto el animal, fiera o sabandija, que como ángel de su guarda había de ser su compañero, y que se conoce por tona de los indios. Cuando el muchachito era capaz de razón, se le hacía entender y comprender cuál era el ángel de su guarda en la carrera de su vida, infundiéndoles groseros errores, hasta persuadirlos de que al tiempo de morir la tona, sin remedio ellos dejarian de existir y no era dificil un golpe de esta naturaleza en ánimo prevenido y en un corazón apocado. El magnetismo, con sus trabajos sobre las imaginaciones exaltadas produce sobre tan locas fantasías efectos prodigiosos, que no son otra cosa que los delirios de una viva agitación.

Hay momentos en que el historiador toma la Biblia para analizar comparativamente algún hecho o alguna situación, y en esto también hay una semejanza con Burgoa.

Hay algunas contradicciones en la vida de Carriedo. Era liberal, anticlerical pero cristiano, es decir se le podría situar en el centro del partido liberal. Sin embargo, cuando tuvo que escoger, su posición fue heterodoxa. "Cuando llegó el Imperio, él como muchos de su tipo creyó que iba a durar mucho tiempo y sirvió al Imperio de Maximiliano; en un viaje a Etla, una guerrilla lo tomó prisionero y lo mató."20

Por esta misma época, hubo otro escritor muy significativo para

24 Estudios históricos... op. cit., p. 91, t. I.

25 Ibidem. p. 56 y 57, t. I.

26 Luis Castañeda Guzmán, entrevista 15 de noviembre de 1985. 
la historia del estado. El padre José Antonio Gay nace en Oaxaca el 13 de junio de 1833 , se hace sacerdote pero debido a los tiempos que le tocó vivir no puede ordenarse en Oaxaca y lo hace a los. 28 años en La Habana. Se puede decir que fue un hombre culto y metódico, con una sólida formación intelectual. Estudió en su ciudad natal y fue maestro en las cátedras de latinidad y filosofía en el seminario.

El mismo explica que "El deseo de ser útil a mi país me obligó a hacer apuntamiento de las noticias que en la lectura fui encontrando relativas a Oaxaca. De estas notas resultó la presente historia.",

\section{Refiriéndose a Gay, Enrique Santibañez dice:}

su Historia de Oaxaca es un monumento literario y científico, que hará pase su nombre a la posteridad; es una obra digna de ponerla en parangón con las mejores que se han escrito, pues en ella campea la más estricta imparcialidad, el más. sano criterio al referir los sucesos y el lenguaje del verdadero historiador, que presenta los hechos tales como los cuenta la tradición o como sucedieron sin tratar de convencer con palabras relumbrantes, sin realzar con una poesía acaramelada los acontecimientos más importantes. ${ }^{28}$

No se puede estar de acuerdo totalmente con esta definición de la Historia de Oaxaca, porque Gay sí toma partido: es sacerdote y además sus ideas van de acuerdo con el partido conservador. Según uno de sus parientes,

era un hombre sereno, apasionado pero no torpe. Arango y Escandón que lo impulsa le aconseja que no es el momento, siendo él quién es, de que saque todo aquello [se refiere a la historia de Oaxaca del siglo $\mathrm{XIX]}$ pues esto haría que su obra no fuera publicada. Por tanto D. José Antonio Gay quita varios capitulos de su obra, sobre todo las cuestiones y opiniones sobre la independencia, por eso su obra no trae lo que es la consumación de la independencia. Hablo de esto por conseja familiar. ${ }^{29}$

27 José Antonio Gay, "Prólogo del autor" en Historia de Oaxaca, México, Biblioteca de Asuntos y Autores Oaxaqueños, 1950, 2 t. en 4 libros.

28 Antonio García Cubas, Diccionario geográfico histórico y biografico de los Estados Unidos Mexicanos, México, s/e, 1899, t. III, p. 135.

29 Entrevista con el Lic. Luis Castañeda Guzmán el 8 de abril de 1982. Es importante hacer una alusión a otros escritos de José Antonio Gay, donde aparecen sus sentimientos políticos más claramente reflejados. Uno de ellos, también facilitado por el Lic. Castañeda Guzmán en el discurso titulado: Necrología del Ilustrisimo Señor Pronotario, tesorero dignidad y vicario capitular del obispado de Oaraca. doctor D. José Maria Alvarez y Castillejos. Que da a luz pública su discipulo el presbitero D. Antonio Gay catedrático del seminario de Oaxaca, México, Imprenta de Andrade y Escalante, 1864. Aquí el padre José Antonio Gay, al hacer la apologia de su maestro y amigo, también externa sin temores su opinión sobre las fuerzas históricas que le tocaron vivir.

"Llegó, en fin, el por tantos motivos funesto para Oaxaca mes de julio de 1859 , en que se publicaron las leyes de lo más furioso de la reforma expedidas por el gobierno liberal residente en Veracruz. La primera consecuencia de este hecho fue la muerte del Ilustrísimo obispo diocesano Dr. D. José Agustín Domínguez que en medio de sus achaques no pudo soportar la profunda tristeza que le ocasionó una medida tan impia como bárbara." Luego sigue haciendo una relación de todos los hombres sabios de la Iglesia que tuvieron que esconderse o exilarse debido a las leyes de reforma.

Muchos otros hombres tuvieron que irse cuando el gobierno pidió el inventario 
Si quisiéramos clasificar de alguna manera este libro del padre Gay, me arriesgaría a decir que es una historia apologética de la Iglesia en Oaxaca, por varias razones: primero no hay que olvidar el momento en que la escribe, que es entre los años de 1865-1875, cuando acaba de pasar la lucha de los años 50, en que el gobierno liberal impuso las reformas que tanto afectaron a los bienes de la Iglesia; luego flotó en el aire un cierto grado de anticlericalismo durante el imperio francés, debido a las ideas liberales del mismo emperador. Gay sacerdote, no fue ajeno a las luchas intestinas que vivió su estado, el país en general y su Iglesia. Esas luchas entre conservadores y liberales, entre federalistas y centralistas, tuvieron sin duda un efecto en él y en su trabajo. ¿Por qué digo que es una historia apologética de la Iglesia en Oaxaca? Porque de alguna manera es la respuesta a todos los acontecimientos políticos del siglo XIX, y especialmente en lo concerniente a los bienes del clero, a su labor en Oaxaca, a la participación que la Iglesia tuvo en la educación. Para un sacerdote, era necesario retomar inteligentemente toda la labor de la Iglesia durante la época de la Colonia y resaltar los aspectos positivos de construcción de iglesias, de escuelas, de obras pias, de trabajo con comunidades indígenas, etc... y en su Historia de Oaxaca, Gay no olvida estos detalles. ${ }^{30}$ Pueden faltarle aspectos sobre el desarrollo económico de la provincia, de la política general del reino o de las costumbres, pero no le falta nada que tenga que ver con la Iglesia de su región.

La ventaja de José Antonio Gay, es que es uno de los pocos historiadores oaxaqueños del siglo XIX que hace referencia a sus fuentes documentales en múltiples ocasiones, y con rigor, lo que permite valorar con criterios más certeros su trabajo. Sus fuentes son: Torquemada, Fr. Jerónimo de Zárate, Diego Muñoz Camargo, Antonio de Herrera, Boturini, Burgoa, Clavijero, Fernando de Alba, Sahagún, Bernal Díaz del Castillo, Alba Tezozómoc y Veitia, entre otros. Gay, un hombre dedicado a la investigación, un hombre de avanzada que merece un estudio más profundo, nos lleva en sus referencias a las técnicas y al método historicista. Es su historia rica en información, y su hilo conductor la participación de la iglesia católica en Oaxaca. Lo cual no quita que dentro de esta corriente sea crítico respecto a algunas personalidades y, como escribió don Jorge Fernando Iturribarría: "Queda también su probidad de historiador veraz cuando reivindicando los prestigios insurgentes de Hidalgo y Morelos, dio un mentis como sacerdote al alto clero que encausando a los dos caudillos epónimos los entregó a la Inquisición, excomulgados". ${ }^{31}$ José Antonio Gay es un historiador que merece un estudio más profundo, por supuesto.

Dentro de la corriente historiográfica que podríamos llamar "Enciclopédica" tenemos a un personaje como Manuel Martínez

de las fincas de la Iglesia mandadas desamortizar. La posición de Gay tan parca y poco crítica en su Historia de Oaxaca, es aquí de clara condena a las leyes de reforma y las épocas bárbaras que le tocó vivir y durante las cuales escribió. No hay dudas sobre las razones por las cuales acortó su historia, terminándola en 1821 .

${ }^{30}$ Gay, Historia de Oaxaca, ibidem.

${ }^{31}$ Jorge Fernando Iturribarría, Introducción a la Historia de Oaxaca, de José Antonio Gay, op. cit. 
Gracida. Nace en Ejutla el 24 de abril de 1847, hijo de Juan Catarino Martínez y Lucrecia Gracida. Su padre murió a causa de las persecuciones ordenadas por Santa Anna, contra quien se pronunció a fines de 1854 .

Hizo los estudios primarios en su tierra natal, trabajó como empleado del gobierno en Ejutla y más tarde en Ocotlán, en la oficina de recaudación de contribuciones "Bajo la autoridad del distinguido fílósofo y hombre público D. Bernardino Carbajal”. Manuel Brioso y Candiani relata que "Ocupada Oaxaca por los franceses el Sr. Martínez Gracida no quiso ocupar puesto público alguno pues él era liberal". ${ }^{32} \mathrm{Se}$ inscribe en el Instituto de Ciencias y Artes y toma varios cursos gracias al apoyo económico del presbítero D. Manuel de Jesús Chávez. Ahí cursó latín, gramática castellana, dibujo, lógica, moral, antropologia; también matemáticas, astronomía y física. Concluye en 1870 , tres años después del derrumbe del Imperio.

En 1870 , año en que era Secretario del Gobierno de Oajaca nuestro vicepresidente el Señor Romero, Martinez Gracida, siguiendo las indicaciones de este jefe, se propuso formar la estadística de aquella entidad federativa en consonancia con los modelos expedidos por el insigne estadista D. Miguel Lerdo de Tejada. Cuadros que no pudo concluir por la emergencia del pronunciamiento de la noria que conmovió hondamente al Estado. ${ }^{33}$

La obra de Martinez Gracida tiene como característica fundamental la cantidad de información que contiene, derivada de sus trabajos como empleado de gobierno:

El 18 de julio de 1878 la Secretaría de Fomento circuló a los gobernadores de los Estados veintiséis modelos para la formación de la estadistica de la república ofreciendo al empleado que se encargue de este trabajo, una gratificación de 200 pesos. Luego que el sr. General D. Francisco Meixueiro recibió esta circular, llamó al Sr. Martínez Gracida y le dió la Comisión, aceptada por este pidió los datos y formó los cuadros de división territorial, censo y movimiento de población, agricultura, Industria, Minería, Instrucción Pública, Bibliotecas, propiedades rústicas y urbanas, etc. La estadística de la Industria es una de las más completas que se hayan formado en el Estado de Oajaca. Comprende 36 cuadros en folio mayor. ${ }^{34}$

Por supuesto el trabajo le significó a Martínez Gracida el reconocimiento de las autoridades del estado y de la Federación. D. Vicente Riva Palacio, ministro de Fomento, escribió una carta halagadora al señor gobernador de Oaxaca, refiriéndose de forma laudatoria al empleado que había realizado el trabajo de la estadística. Asimismo, envió un premio de cien pesos al empleado. Terminados los cuadros, el Sr. Martínez Gracida recibió 200 pesos más.

32 Manuel Brioso y Candiani, "D. Manuel Martínez Gracida, Historiador de Oajaca", revista El centenario, año I, núm. 3, Oaxaca, 15 de octubre 1910, p. 58-66.

33 Ibidem, p. 58 .

34 Ibidem, p. 59. 
Los cuadros permanecen en la Secretaria de Fomento y se encuentran firmados en su mayor parte por el Lic. D. Nicolás López Garrido, secretario del Gobierno.

Cuando el 1 de diciembre de 1881 el general Porfirio Díaz llega a la gubernatura del estado, nombra a Martinez Gracida oficial mayor de esa Secretaría el 24 de mayo de 1882 en sustitución del Lic. Francisco Pérez. Desempeñó el puesto hasta el 29 de julio para ocuparse nuevamente de la Sección $2^{\mathrm{a}}$ de la Secretaría de Gobierno.

Los trabajos sobre estadística de Oaxaca, ganaron para el autor el respeto y la consideración de los gobernantes. Por ese motivo el presidente de la República, Porfirio Díaz, le encarga la formación de la estadística de los negocios, de lo civil y de lo criminal, del estado de Oaxaca, que habían pedido a la Corte de Justicia de la misma entidad. Con seis empleados que le proporcionaron y trabajando del 20 de marzo al 9 de mayo de 1889 , formó la mencionada estadística, remitiéndola al gobierno estatal a cargo entonces del Gral. Albino Zertuche (gobernador) y al Lic. Federico Sandoval (secretario de gobierno).

Durante todo el Porfiriato, Manuel Martínez Gracida desempeña un importante papel como empleado público del gobierno del estado. Es uno de los servidores públicos que hace más aportes en la organización de Hacienda y fiscalización. Conoce muy bien la región y viaja con los gobernantes a sitios conflictivos, tales como el Istmo y Tuxtepec, donde actúa en gran medida como consejero de gobierno. En su autobiografía, según Manuel Brioso y Candiani, él mismo lo expresa de la siguiente manera:

Conozco casi las dos terceras partes del estado, y me conocen también casi todos los particulares y autoridades de los pueblos, por las relaciones que con unos y con otras he tenido durante el tiempo que he servido en la Secretaría, y a quienes he tratado con cortesía, procurándoles el pronto arreglo de sus negocios.

A propósito de estas relaciones, he dirigido durante mi larga carrera de empleado, cerca de 30000 cartas a autoridades, empleados y particulares, ya en solicitud de datos históricos y estadísticos, o ya instruyendo o aclarando a las primeras las disposiciones administrativas, con el fin de facilitarles el buen servicio público. ${ }^{35}$

\section{También reconocen su valía varias instituciones mexicanas:}

Además del nombramiento de miembro corresponsal de la Sociedad de Geografía y Estadística, que obtuve el 27 de noviembre de 1880, fui socio fundador del 'Liceo Oaxaqueño', corporación que no existe ya. En 14 de agosto de 1883, fuí nombrado Agente del gobierno, en la Junta Auxiliar de Estadística, y el 21 de marzo de 1885, socio honorario del "Liceo Ignacio M. Altamirano" el cual dejó de existir en Oajaca desde 1890. El 21 de octubre de 1886 me agració la Sociedad Mexicana de Historia Natural con el nombramiento de socio honorario; el 29 de enero de 1888 , con el de igual clase, la sociedad científica, "Antonio Alzate", y también la Sociedad de Geografía y Estadística, con igual honra, en mayo del mismo año. Posteriormente, en 24 de febrero de 1893, fuí nombrado por el Distrito de Juxtlahuaca, delegado de la 
Sociedad Agrícola, y el 26 de agosto de 1864, miembro honorífico de la Sociedad Pedagógica 'Benito Juárez'. ${ }^{36}$

La participación política de Martínez Gracida y el reconocimiento a sus dotes de estadista lo llevaron a la Cámara de Diputados.

Encontrábame prestando mis servicios en la importante oficina de Estadística, cuando fuí electo Diputado propietario a la $\mathrm{H}$. Legislatura del Estado, el 14 de julio de 1895, por el círculo electoral de Tehuantepec, cargo que me hizo volver a la Capital y que desempeñaba desde el 16 de septiembre del mencionado año.

Clausuradas las sesiones del Congreso, volvi a México encargándome nuevamente de lo que me correspondía en la Dirección Gral. de Estadística. $^{36}$

$\mathrm{Su}$ época de mayor actividad administrativa es la década de 1890 durante la cual cubre varios puestos por su comprobada probidad como funcionario (que no le reditúan beneficios de tipo económico):

Por designación del Ministro de Fomento, me encargué, volviendo a Oaxaca, de las operaciones del censo en dicho Estado, las que interrumpi, pues habiendo sido nombrado Administrador del Timbre en Tlaxiaco, tuve que marchar a esta importante ciudad de la Mixteca. No duré en ese cargo mucho tiempo, pues fuí promovido para la administración de la Aduana Marítima de Acapulco. Allí, después de los trabajos de mi oficina, me dedicaba por algunas horas diarias, a formar la Nomenclatura Geográfica del Estado de Guerrero; mas habiéndome enfermado del paludismo, tuve que volver a Oaxaca, donde pronto me restablecí. Cuando me hallaba en Tehuantepec, para volver a mi empleo de Acapulco, recibi el nombramiento de Administrador de la Aduana Maritima de Campeche; y como aceptara dicho puesto, marché al puerto de referencia, y el 19 de marzo de 1903 me hice cargo de la Administración. Allí, el Gobernador D. José Castellot, que supo cuál era mi manejo correcto con el comercio, y cómo cumplía la ley, me visitó, mostrándose complacido de que ocupase yo aquel puesto.

Finalmente el Sr. Presidente de la República, Gral. D. PorfirioDíaz, que siempre ha estimado al historiador oajaqueño desde que lo tuvo a su lado en la Sria. del Gobierno de Oajaca, y que habia acordado los nombramientos para empleos federales, dispuso en 5 de diciembre de 1906, que fuese nombrado Administrador del Timbre en Guadalajara. $^{37}$

Destaca Manuel Martínez Gracida como hombre cuya vida está dedicada a servir a Oaxaca desde el ámbito del servidor público, el empleado público y el de la pluma. Tiene conciencia clara de lo importante que para la mejor administración del estado puede ser la estadística y el orden. Por otro lado sabe la importancia que la historia tiene para los oaxaqueños pues por ella podrán encontrar su verdadera identidad y sentirse más seguros de si mismos. "Para formar la historia de los indios oajaqueños, ha trabajado 28 años 
que significan muchos dolores y gastado más de doce mil pesos, lo que revela un número de privaciones." 38

Manuel Martinez Gracida es muy conocido por su libro Cuadros sinópticos, estadísticos y geográficos de Oaxaca, publicado en 1883 , que puede ser considerado casi como una enciclopedia de los pueblos, ranchos y haciendas de la región por la amplia y valiosa información que proporciona sobre ellos y sobre cada uno de los municipios, de los distritos de su organización, de sus principales acontecimientos históricos, sus fenómenos naturales... sin dejar de mencionar la ubicación geográfica, las vías de comunicación, el clima, etc. Sin duda, la obra está influida por los libros de visita que realizaban los obispos de Antequera durante la época colonial y más aún por el cuestionario que en 1802-1804 mandó realizar don Antonio Bergoza y Jordán. ${ }^{39}$

Obras de este mismo autor son: Los indios oaxaqueños, sus monumentos arqueológicos, zapotecos y mixtecos (1888), Flora y fauna del estado libre y soberano de Oaxaca (1891), La historia de la fundación de Oaxaca (1894). Este último permanece inédito, al igual que muchos otros. 40

Escritor y compilador prolífico, cabe mencionar otro aspecto interesante de Martinez Gracida: sus cartas a Cayetano Esteva en las que narra algunos aspectos de su vida, de su familia, de sus preocupaciones. Muere en Guadalajra desde donde escribe a sus amigos. ${ }^{11}$

Siguiendo nuestra cronología historiográfica, se puede decir que en la época porfirista hay varios hombres ilustres oaxaqueños que, preocupados por la educación y en particular por la enseñanza y el aprendizaje de la historia, elaboran libros de texto con este fin. Entre ellos mencionamos a Cayetano Esteva, Victoriano Báez, Francisco Belmar, Demetrio Navarrete (aunque este último se dedica más bien a la geografia). ${ }^{42}$

Comenzaremos por Cayetano Esteva, nacido en Oaxaca en 1863

38 Ibidem.

39 Cuestionario de don Antonio Bergoza y Jordán, obispo de Antequera a los señores curas de la diócesis, I. Irene Huesca, Manuel Esparza, Luis Castañeda Guzmán, documentos del Archivo, Archivo General del Gobierno del estado de Oaxaca, 1984, 2 t.

${ }^{40}$ Estadísticas, entre las cuales la de Agricultura mereció un diploma concedido en la Exposición de Productos del Estado, celebrada por la sociedad de artesanos en su capital. Varios cuadros sinópticos, estadísticos y cronológicos. El del pueblo de Mitla está citado por el Sr. Peñafiel, en las "Notas bibliográficas de la gramática de la lengua zapoteca". Distintas biografías de oaxaqueños notables y relaciones sobre acontecimientos históricos del estado, entre las cuales sobresale la Relación histórica de los sucesos notables del Estado, desde 1601 hasta 1890 . Sobre esta obra hizo el Periódico Oficial del Gobierno de dicho estado, un extenso comentario que puede verse en el núm. 74 del tómo XII. También el periódico $L a$ Patria entró en amplias consideraciones acerca de ella en aquellos dias, insertando una carta encomiástica de D. Carlos Alvarez Vassern, que tenemos a la disposición de los lectores de esta reseña. Escribió igualmente sobre Nomenclatura Geograficoetimológica del estado de Guerrero, que mereció un halagüeño comentario del historiador de Campeche, don Gustavo Martínez Alomia. También es Gracida autor de las Efemérides sobre la guerra de Reforma y la intervención y el Imperio en Oaxaca.

- En la biblioteca de la Universidad de Nuevo México, en Albuquerque, en la sección Special Colections se encuentra el Archivo que perteneció al señor Van de Velde y que contiene documentos sobre Oaxaca, la correspondencia de Manuel Martinez Gracida a Cayetano Esteva.

42 Francisco Belmar, Breve reseña histórica y geográfica del estado de Oaxaca, Oaxaca, Imprenta Comercio, 1901. 
y muerto ahi mismo el 30 de abril de 1930. Hace sus estudios de profesor normalista en la misma ciudad y obtiene el título de maestro en 1887. Ejerce el magisterio en Ixcatlán, Tuxtepec, Juxtlahuaca, Tehuantepec y Oaxaca. Pasa como profesor adjunto a la escuela práctica, anexa a la normal; se le nombra director de la Escuela de Nochixtlán y profesor de la escuela superior número dos, al lado de Abraham Castellanos y, finalmente, en la escuela Porfirio Díaz (1909). En enero de 1907, es nombrado director de la biblioteca del estado. En este lugar continúa haciendo estudios históricos. Sus escritos más representativos son los siguientes: "La historia de la imprenta en Oaxaca", Nociones elementales de geografia histórica del estado de Oaxaca (1913), "El pequeño ciudadano", "Geografía del distrito del Centro" y "El ciudadano oaxaqueño". ${ }^{43}$ Como periodista, colabora en los siguientes periódicos y revistas: Voz de la verdad, El centenario, Oaxaca progresista, El correo del Sur, El heraldo de Oaxaca, El Estandarte, Oaxaca libre, El regional y El liberal oaxaqueño. En la revista El centenario, publica un pequeño ensayo titulado "A propósito del censo; cuadro estadistico" donde hay algunos datos indicadores de la visión del historiador. Se trata de un censo que va de 1792 a 1910: la información, según dice, procede de diversas bibliotecas oficiales $y$ particulares, y ha recurrido al auxilio de manuscritos fidedignos.

Considerando que este ligero trabajo puede ser de gran utilidad para el historiógrafo, estadista, sociólogo, y aun para el médico, no hemos vacilado en reunir los datos más precisos o más aproximados a la verdad.

ve esta manera, aunque no con exactitud, el autor se refiere a su trabajo de investigación. Cuando menciona el aumento y disminución de la población durante el siglo XIX vuelve a citar sus fuentes documentales:

Las guerras intestinas disminuyeron en gran parte el número de hombres aumentando el de mujeres, por lo que subió la población desde ese año al de 1843 a 511776 y lo que es más notable, es que el año siguiente aparece un censo de... 521556.

A partir de estos años la población fue aumentando en los distritos, pero en la capital disminuyó bastante; primero, por las guerras, y segundo, por la epidemia del tifo llamado entonces tabardillo pinto que atacó, más a los hombres que a las mujeres según constancias fidedignas de los archivos parroquiales...

Según las concentraciones hechas en las diversas parroquias de esta Diócesis y en las subprefecturas en que quedó dividido el Estado, se nota perfectamente que desde 1838, comenzó a subir el censo, dándose el caso de que en varios lugares, fue mayor el número de hombres que de mujeres, por lo que aumentó la criminalidad y el alcoholismo, señalándose como delitos o crímenes: infanticidios, estupros, raptos y en muchos casos el homicidio; pero estos eran más frecuentes fuera de la capital, porque desde 1850 a 1868 , las levas hacian a los solteros y viudos que refrenaran sus pasiones por el terror que les causaba ingresar a las filas de ejércitos acontendientes. ${ }^{44}$

${ }^{43}$ Cayetano Esteva, Elementos de Geografía del Distrito del Centro. Para uso de las escuelas de instrucción primaria. Oaxaca, La Voz de la Verdad, la. del 2 de abril, letra B, 1911 .

${ }^{4}$ Cayetano Esteva, "A propósito del Censo: Cuadro estadístico" en la revista El centenario. Año 1, núm. 3, Oaxaca, 15 de octubre, 1910, p. 73-74. 
Hay en él interés de hacer una historia que se apegue a los números y al prestigio de la estadística, pero a la vez cae en ambigüedades y aparentes contradicciones.

Victoriano Báez, al igual que Cayetano Esteva, escribe sobre la historia de Oaxaca y podría decirse que ambos están influidos por la corriente positivista que se dio en la República durante el porfiriato "cientificista". Su Compendio histórico de Oaxaca (1909) fue pensado para las escuelas primarias y secundarias del estado y su interés estriba en que en él se encuentran reflejadas las ideas de una época en que el grupo que ostentaba el poder era conocido como "los científicos". Es decir todo el positivismo estaba fluyendo de diferentes formas en la República mexicana. $Y$ estas ideas son las que permearán el desarrollo educativo y la enseñanza de la historia estatal.

Victoriano Báez se incluye en esta corriente, según la cual el conocimiento de la historia debía redundar en una acción positiva para el pais, cuando dice:

La historia es la maestra del mundo... su estudio no es simplemente material de adorno, sino labor de cultura, algo muy esencial de la educación y de lo menos prescindible para el hombre civilizado. 45

Pero por supuesto, lo que interesa en este proyecto educativo a don Victoriano Báez no es cualquier tipo de historia sino la historia patria y más aún la regional, que debía ser considerada con un sentido claro para el pueblo y por eso dice: "La historia patria tiene tal interés para cada pueblo, para cada individuo, que sin ella es difícil la emulación de progreso, imposible la enseñanza cívica y el florecimiento del patriotismo." 46 Para él, la utilidad de la historia es clara.

Es importante una identidad para reafirmarse, él dice que a través del conocimiento de la historia se logra esta identidad. Debe comenzarse con el estudio de la tierra natal, de lo propio, de lo que nos rodea, del suelo en que vivieron nuestros padres y en donde nosotros mismos nos hemos iniciado en la vida, donde hemos luchado, conocer la historia de nuestro pueblo, de nuestra ciudad, de nuestro estado, las leyendas y episodios del terruño, los héroes, los hombres ilustres, los benefactores, los gobernantes, la raza autóctona, los nombres indígenas, la religión y las costumbres, es conocer lo que más nos interesa y lo que más nos dispone al aprendizaje de la historia patria completa y de la historia universal. ${ }^{47}$

Aquí vemos una corriente de ideas y de propósitos. No era sólo estudiar o escribir cualquier tipo de historia, sino hacer una historia con todo un significado de finalidad. Era hacer la historia para objetivos muy precisos. El estudio de la historia, local o regional, de la historia patria, tenía la función de crear una identidad nacional y local.

Este escritor fue fundador de la iglesia metodista en Oaxaca y lo

45 Victoriano Báez, Compendio histórico de Oaxaca, Oaxaca, talleres tipogrăficos de Julián S. Soto, 1909, p. I y II.

t6 Ibidem., p. 30.

47 Ibidem. 
mismo que Cayetano Esteva, fue profesor de escuela primaria. Es autor, además, del compendio: Episodios históricos de la guerra de intervención y el segundo imperio (editado por Julián S. Soto, Oaxaca, 1907). Se consideraba entre los buenos liberales, esto es, un liberal mexicano antes de la Revolución. Sus fuentes son: Burgoa, Gay, Martínez Gracida; en ningún momento habla de fuentes documentales que haya consultado personalmente.

Dentro de la historiografía oaxaqueña del siglo pasado y principios de éste, merece nuestra atención Manuel Brioso y Candiani porque su trabajo no se reduce solamente a escribir la historia del estado, sino también sobre México, con lo que él considera debe ser el "método científico", según su maestro Xenopol.

Brioso y Candiani nace en la ciudad de Oaxaca el 30 de septiembre de 1859. Realiza sus primeros estudios en el Colegio Católico de Oaxaca, donde permanece entre los trece y quince años (1872-1876). De ahí pasa al Instituto de Ciencias y Artes del estado. Fue alumno estudioso y obtuvo varios diplomas y menciones honorificas y, en 1882, antes de su último examen, es nombrado catedrático por oposición y en prioridad de la clase de psicología, lógica y moral del mismo Instituto. A los 24 años (1883) obtiene el testimonio de su último examen profesional. Empieza entonces su vida pública que puede dividirse en dos lapsos; el primero, de su estancia en Oaxaca y que comprende hasta 1901, es decir dieciocho años, y el segundo, en la ciudad de México donde residió hasta su muerte, acaecida en 1945, cuando contaba 86 años de edad.

En realidad, si nos guiamos por lo que el propio escritor señala de cómo concibe la historia, vemos que su enfoque es muy distinto al de los demás historiadores oaxaqueños. Habla de un método histórico según el cual se plantea no sólo la historia de $\mathrm{Oa}$ xaca, sino inclusive la de México. ${ }^{48}$

Lo que llama la atención es que la Historia de México esté escrita y publicada en Oaxaca (1889). Presenta el libro de la siguiente manera:

Arreglada bajo un plan filosófico enteramente nuevo y dispuesta en lecciones, la obra contiene las monografias de los grandes hechos, las biografias de los grandes hombres y la descripción de las grandes épocas que se encierran en el México histórico y está destinada a la enseñanza del ramo en la instrucción secundaria y especialmente a los alumnos del Instituto de Ciencias, academia de niñas, y Escuela normal de profesores en Oaxaca.

Sus opiniones expuestas en la parte denominada Al lector, son muy criticas de la historia que existia hasta ese momento:

Las muchas obras publicadas hasta hoy sobre la historia de México, ya rudimentarias o destinadas a la instrucción secundaria, aunque más o menos bien acomodadas al objeto que se han propuesto sus autores, no contienen, sin embargo, en mi concepto, aquel fondo filosófico dominante que es tan necesario para nutrir la inteligencia, ensayándola en

${ }^{48}$ Maria Teresa Vidal Hernández, El método histórico de Manuel Brioso y Candiani, México, tesis para obtener el grado de maestría en historia, Universidad Nacional Autónoma de México, Facultad de Filosofía y Letras, 1970. 
la provechosa actividad del razonamiento. Las obras rudimentarias contienen aglomeraciones más o menos estériles de nombres propios y de fechas para recargar inútil y hasta dañosamente la memoria de los escolares, y en cuanto a las destinadas a la instrucción secundaria o no son completas o contienen abundancia de detalles frívolos o inconducentes, para un estudio propiamente científico de la historia patria. ${ }^{49}$

Brioso y Candiani escribe también otras obras, tratados de lógica, de gramática, novelas, epistolarios, en especial Epistolario técnico, con veinte cartas de amor redactadas en el lenguaje de las profesiones, ${ }^{50}$ y por supuesto sus libros sobre Oaxaca.

Para Brioso y Candiani según María Teresa Vidal Hernández, que ha escrito su tesis de Maestría para la UNAM sobre este historiador:

El problema capital del estudioso de la historia es la fijación de verdades mediante la estricta determinación de las causas. Por no hacerlo así falló Taine, según Xenopol y fallaron Alamán y Bustamante, según Brioso y Candiani, ni el historiador francés ni nuestros dos mexicanos hicieron historia sino obra partidista.

En lugar de atender al encadenamiento necesario de los hechos que estudiaban, creyeron conveniente juzgarlos, con lo cual se apartaron del verdadero terreno de la historia e imaginaron que los hechos históricos podian ser distintos de lo que verdaderamente eran. ${ }^{52}$

En 1939 Brioso y Candiani redondea su concepción de la historia y su método científico, siguiendo la orientación del profesor rumano Xenopol. Candiani acepta de Xenopol su posición evolucionista pero esto no quiere decir que no lo critique en algunos aspectos que considera contradicciones de teoria.

En muchos otros aspectos, no tiene dudas de que la teoría de Xenopol es la apropiada para la historia, y nos da un ejemplo:

Para el citado profesor rumano, los hechos, que él llama de sucesión y que son realmente los hechos históricos, se deben a la inteligencia del hombre y no a los impulsos de la materia, aunque ésta de algún modo pueda influir en darles alguna dirección. Además de eso, tales hechos han de corresponder a la evolución, pues si no han contribuido a ésta, podrán servir al novelador, al cronista y a los que buscan en la historia la simple verificación de los sucesos; por ejemplo en mi tierra natal y hace muchos años, se verificó una ascensión aerostática; sucedió que un mirón fue arrastrado al arrancar el globo de la tierra, por un cable que se le enredó en un pie; el suceso fue emocionante, pero no fue un hecho histórico, porque en nada se refirió a la evolución del pueblo oaxaqueño, pues ni se derivó de otros hechos sociales de importancia, ni dio origen a otros hechos. En cambio, la desaparición del general

${ }^{44}$ Manuel Brioso y Candiani, Historia de México, t. I, $1^{\text {a }}$ edición, Oaxaca, Imprenta del Estado, en la escuela de artes y oficios a cargo de Ignacio Candiani, 1889.

- ${ }^{50}$ Brioso y Candiani, Manual Epistolario técnico; veinte cartas de amor redactadas en el lenguaje de las profesiones, México, Ediciones Núñez, 1926.

si La evolución del pueblo oaxaqueño desde la conquista hasta la consumación de la Independencia 1521-1827, México, D. F., 1939, ensayo de una historia científica acerca de Oajaca, Tip. Oaxaca México. La evolución del pueblo oaxaqueño desde la adopción del Plan de Ayutla hasta el fin de la guerra de Reforma. Tacubaya, Imprenta a su orden, 1945.

${ }^{52}$ María Teresa Vidal, op. cit., p. 30. 
Félix Díaz, padre, se originó de la participación de éste en la revuelta de la Noria, que dio por resultado que los borlados ocuparan el poder. Este sí fue un hecho histórico o de sucesión. ${ }^{53}$

Luego, en su apreciación de la historia, Brioso y Candiani, considera que hay hechos de Sucesión y que éstos son los que hacen que la historia evolucione.

Muchos más son los historiadores oaxaqueños que de una manera u otra han buscado participar en la creación de la identidad oaxaqueña. Sólo he tocado a algunos, principalmente del siglo XIX, aun cuando se ha aludido a dos o tres anteriores.

Lo más relevante de la historiografía oaxaqueña es que ha sido siempre escrita y consumida por un reducido número de personas, entre otras cosas porque el otro lado de la moneda, la historia de los pueblos y de las comunidades zapotecas, mijes, mixtecas, chatinas, etc., apenas se empieza a recuperar ahora. Son las propias comunidades las que están buscando en sus archivos la verdad sobre su pasado y su relación con el exterior. 